\title{
Learn to be Good to Your Back and Your Back Will be Good to You!
}

\author{
Mahendra Gudhe $^{1}$, Sohael Khan ${ }^{2 *}$, Shraddha Singhania ${ }^{3}$ and Vandana Gudhe ${ }^{4}$ \\ ${ }^{1}$ Spine Fellow, Shriniwas Orthopaedic Nursing Home, India \\ ${ }^{2 *}$ Department of Orthopaedics, Jawaharlal Nehru Medical College, India \\ ${ }^{3}$ Department of Radiology, Jawaharlal Nehru Medical College, India \\ ${ }^{4}$ Clinical Physiotherapy Fellow, Sancheti Orthopaedic Hospital, India
}

Submission: April 24, 2017; Published: May 02, 2017

*Corresponding author: Sohael Khan, Department of Orthopaedics, Jawaharlal Nehru Medical College, India, Email: drsohaelkhan@hotmail.com

\section{Editorial}

Back and neck pain is one of the most common reason for sick leaves. Each one of us had this problem some or other time. Statistic states that 50 percent of the working population suffers from this element once in a year. Lifting heavy weight, sitting on stiff backed chairs in office, bean bags, prolonged driving, abnormal sitting postures, use of thick pillow can leads to back and neck pain.

Have you ever heard have a Back or neck transplant? We haven't either. Since you only have one spine take of it daily.

Spine Care includes:

A. Proper Back Support: One must sit on a chair that has proper back support with hips all the way behind and legs supported flat on the floor. This will ensure that pressure is distributed equally throughout the spine.

B. Reduce stress on the spine: Keep object closer to your body while lifting. Bend the knee while lifting avoiding stress on spine.

C. Avoid carrying heavy bags: This Creates a lot of pressure on the shoulder and back. One should adjust straps to make sure that it does not sag down to hips.

D. Stretching and strengthening of muscles: Root cause for back and neck pain are weal spinal muscles. Do few

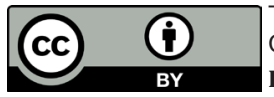

his work is licensed under Creative Commons Attribution 4.0 License

DOI: $10.19080 /$ OROAJ.2017.06.555691 stretching exercise daily. Take breaks, avoiding prolong sitting. Gym-goers should always begins their workout with warm up and end with cool down exercises. Don't do highend activities with weak muscles.

Management of Low back pain involves many specialties - neurosurgeons, orthopedist, physiatrist, physiotherapist - everyone with different knowledge and experience, which all play an equally important role [1]. Realizing the need for creating awareness about Spine problems and Spinal Cord Injury and the fact that Spinal Cord injury can lead to a fully inclusive life if managed appropriately, International Spinal Cord Society has decided to launch an international campaign to observe 5th September as a SCI day [2].

\section{Always remember}

"If the wheels are misaligned, premature wear and tear of car's tires occurs, same holds true for human body if the spine misaligned"

\section{References}

1. Landi A, Grasso G, Colistra D, Ambrose A, Define R (2016) Clinical Assessment of Low Back Pain: A Neurosurgical Point of View. Int J Recent Surg Med Sci 2(2): 55-57.

2. Chhabra HS, Bhatra S (2016) Spinal Cord Injury and its Impact on the patient, Family, and the Society. Int J Recent Surg Med Sci 2(1): 1-4.

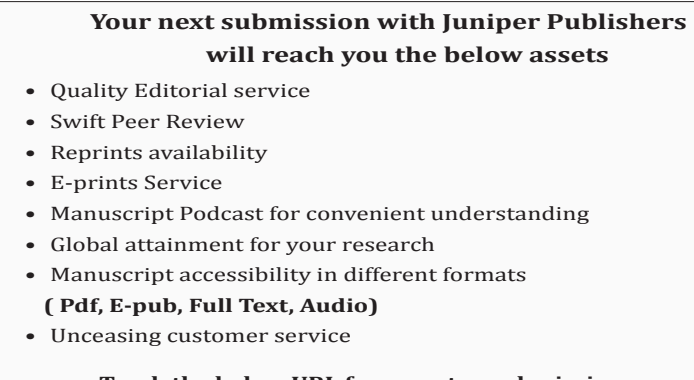

Track the below URL for one-step submission https://juniperpublishers.com/online-submission.php 